Economía, Sociedad y Territorio, vol. vIII, núm. 26, 2008, 415-449

\title{
Naturaleza y dimensión del rezago habitacional en México
}

\author{
IgnaCio KunZ-Bolaños* \\ Irma Guadalupe Romero-Vadillo***
}

\begin{abstract}
This paper estimates the importance and nature of the housing backwardness in Mexico. The vast majority of calculations do not identify clearly the deficiencies derived from overcrowding nor do they explain the shortages produced by poor housing quality. In this work we consider four kinds of deficit: a) units that do not fulfil the minimum conditions to define them as housing (2 million), b) deficit produced by family extensions and additional homes (8 million), c) qualitative deficit, in other words, the deficit resulting from poor conditions or bad equipping of houses (10.3 million) and d) other non-desired situations (0.7 million). In order to obtain these estimates we have used the census figures for the year 2000.
\end{abstract}

Keywords: housing, housing needs, housing backwardness, 2000 census sample.

\section{Resumen}

El presente artículo estima la dimensión y naturaleza del rezago de vivienda en México. La mayoría de los cálculos no identifican plenamente las deficiencias derivadas del hacinamiento y tampoco las carencias que se producen por la mala calidad de las viviendas. En este trabajo se estiman cuatro grandes tipos de déficit: a) las unidades que no cumplen con las condiciones mínimas para definirlas como vivienda (2 millones); b) el déficit producto de las extensiones familiares y hogares extras (8 millones); c) el déficit cualitativo, es decir, el que resulta de la mala condición o escaso equipamiento de las viviendas (10.3 millones); y $d$ ) otras situaciones no deseadas (0.7 millones). Para realizar la estimación se utilizó la muestra censal del año 2000.

Palabras clave: vivienda, necesidades de vivienda, rezago habitacional, muestra censal 2000 .

\footnotetext{
*Universidad Nacional Autónoma de México. Correo-e: kunzbo@servidor.unam.mx.

** Instituto Politécnico Nacional, México. Correo-e: iromerov@ipn.mx.
} 


\section{Introducción ${ }^{1}$}

Existe consenso internacional en que, sin duda, la vivienda es una de las necesidades humanas más importantes. En términos de Bradshaw (citado por Pinch, 1997: 5-6), es una necesidad sentida, expresada, comparativa y, como en el caso mexicano, normativa. A pesar de que no es tan imperativa como la alimentación, en muchos países, México entre ellos, la vivienda se ha convertido en el centro de las políticas sociales. Las necesidades de alimento, vestido y ciertos aspectos de la salud pueden ser atendidas de una $\mathrm{u}$ otra forma por la familia, las organizaciones de caridad y los mercados privados; sin embargo, la naturaleza del bien vivienda hace particularmente difícil la solución a través de cualquiera de estos agentes y requiere mayor intervención del Estado, tanto por la cuestión del acceso al suelo y el alto costo de ésta y sus implicaciones en los mercados de dinero, como por el papel del hábitat que soporta a la vivienda y que es, sin duda, una responsabilidad pública.

De esta manera, el tema de la vivienda es de interés público y requiere la intervención del Estado, los que supone el diseño de políticas públicas que, como tales, no son ajenas a la estructura social e ideológica de la nación que la implementa. En México, como en muchos otros países, se ha pasado de un Estado benefactor caracterizado por la provisión directa de bienes, hacia una política de provisión de bienes exclusivamente públicos, dejando los bienes de consumo individual (Samuelson 1954), como la vivienda, a los mercados privados.

En este trabajo no pretendemos hacer un análisis exhaustivo de la política de vivienda -tema que escaparía a cualquier artículo que quisiera abordarla de manera seria-, pero sí evaluamos uno de los aspectos iniciales de la política que de manera general se podría definir como la magnitud del problema. Las estimaciones oficiales del problema de vivienda en México son excesivamente moderadas, no reconocen ni el tamaño ni la naturaleza del déficit. El por qué de esto lleva a dos posibles explicaciones: una presentación reducida de la problemática para ocultar su verdadera dimensión y la incapacidad del Estado para enfrentarla o, simplemente, por la impericia técnica de los responsables de la política. De acuerdo con lo que afirman Gustavo Garza y

${ }^{1}$ Agradecemos la colaboración de Eleonora Romero Vadillo, por la asesoría y revisión de los programas de cómputo, y la de Erandi Martínez García en el manejo de la información. 
Martha Schteingart, "la forma en que se mida la cantidad de viviendas necesarias es lo que determina las políticas, estrategias, plazos y recursos necesarios para tratar de solucionar el problema" (1978: 14).

En este artículo se presenta una estimación del déficit habitacional en México con base en la muestra censal del año 2000. Para esto se construyó el concepto de lo que sería una vivienda digna y decorosa, teniendo en cuenta la realidad de la sociedad mexicana y la posibilidad real de medirla con los indicadores disponibles. Las unidades familiares que no cuentan con una vivienda o si ésta no cumple las condiciones que la definen como digna y decorosa, se consideran deficitarias.

A partir de este marco de referencia, se determinan, en primer lugar, los requerimientos de vivienda nueva tanto para las familias que ahora no cuentan con una, como para aquéllas cuya vivienda o refugio no cumple con la función mínima de protección y desarrollo sano de sus ocupantes; posteriormente se evalúan las condiciones de espacios, servicios, protección y seguridad jurídica como calificativos de la vivienda, lo que determina la naturaleza y magnitud de las mejoras requeridas por las casas existentes. Por último se concluye con una comparación con los informes oficiales del rezago de vivienda, haciendo énfasis en las diferencias entre los cálculos y se evalúa la actual política en este tema respecto de su posibilidad de resolver el problema.

El concepto de déficit aquí utilizado tiene como referente la construcción de la definición de los requerimientos mínimos que debe incluir una vivienda digna y decorosa (siguiente apartado), de manera que el déficit tiene una implicación cuantitativa cuando se refiere a las viviendas necesarias para cubrir las necesidades de las familias que no cuentan con una o que la que tienen no se puede considerar como tal; y una implicación cualitativa, cuando las viviendas carecen de las cualidades consideradas en la definición de lo digno y decoroso.

\section{Problema de la definición de vivienda digna y decorosa}

Desde el siglo XIX, Max Weber y otros sociólogos cuestionaron la objetividad de los procesos sociales pretendida por los positivistas e insistieron en el significado subjetivo del comportamiento humano, y propusieron dirigir la investigación hacia el entendimiento de este comportamiento más que hacia la explicación generalizada. 
A mediados del siglo xx las críticas al objetivismo social estaban muy extendidas desde diferentes perspectivas y en las últimas décadas se convirtieron en el pensamiento dominante. Jacques Derrida (citado por Travers, 2004: 18) establecía que no había un significado fijo para ningún texto, en lo que incluía los informes sobre vivienda que producían los investigadores para las agencias de gobierno.

En este mismo sentido, P. Winch argumentaba que la investigación sociológica debería involucrar el entendimiento de los papeles que constituyen diferentes áreas de la vida, en lugar de intentar construir una teoría científica que explique la acción humana (citado por Travers, 2004: 19). Cada forma de vida o juego del lenguaje se tiene que entender en sus propios términos (ibidem). A estos planteamientos se deben agregar los de muchos otros autores, como Thomas Kuhn quien desarrolló la idea de los paradigmas en las comunidades científicas, que hacen que la realidad se contemple desde una sola perspectiva, lo cual sólo puede superarse cuando el paradigma entra en crisis y lo sustituye uno nuevo, que generalmente no aceptan los defensores del anterior.

Este conjunto de ideas llevó a lo que se conoce como relativismo: “...es la condición social la que determina lo que será aceptado como conocimiento [...] no hay ningún principio absoluto o criterio independiente de la determinación social. Por lo tanto, no hay bases seguras para el conocimiento humano: todo el conocimiento es relativo (Hughes y Sharrock, citados por Travers, 2004: 21).

En general, el relativismo no niega la existencia de un mundo objetivo sino que plantea el problema del conocimiento relativo de ese mundo objetivo. En esta línea, las ideas relativistas tuvieron influencia en el construccionismo social en los años sesenta del siglo pasado, el cual plantea que las aproximaciones al conocimiento de la realidad y las acciones humanas son elaboraciones o construcciones condicionadas por creencias, valores e intereses. Desde el punto de vista metodológico, el construccionismo busca comprender esas elaboraciones.

En este contexto de ideas, la definición de lo que es una vivienda digna y decorosa es, sin posibilidad de evasión, una construcción social y por tanto, la definición que se propone aquí se reconoce como relativa, sujeta a una argumentación que pretende ser coherente y razonable, pero no tiene pretensiones de verdad. Aunque la Constitución Política de los Estados Unidos Mexi- 
cano introduce el concepto de vivienda digna y decorosa en su artículo $4^{\circ}$, no define su significado y alcance. Sin embargo, el planteamiento de este trabajo es que la estimación del déficit de vivienda, entendido éste como toda situación habitacional que no es digna y decorosa, requiere necesariamente definir estos conceptos y reconocemos que esto implica una construcción conceptual condicionada por los valores, ideas, intereses y conceptos que sirvieron de base a los autores.

La relatividad de estas construcciones tiene medida. Ludwig Wittgestein y P. Winch, considerados por algunos como relativistas, están convencidos de que habitamos un mundo objetivo al que es posible aproximarse con base en el entendimiento compartido y el cuidado del lenguaje (Travers, 2004: 19). Es decir, el relativismo se puede reducir a través de un lenguaje intersubjetivo y por medio de acuerdos y convenciones sobre la realidad social, que ciertamente pueden llegar a constituir un paradigma, pero evitan un subjetivismo a ultranza en el que la realidad se restringe a lo que cada individuo considera. En tal sentido, en este trabajo se presenta una reflexión detallada de lo que se considera digno y decoroso para una vivienda haciendo explícitas las referencias conceptuales a manera de explicar nuestra propia construcción; la definición de lo digno y decoroso resulta indispensable para estimar el déficit en México y esta medición es, a su vez, un requerimiento para diseñar o evaluar la política de vivienda, que a final de cuentas, tiene como principal objetivo abatir el déficit y cumplir con lo establecido en el artículo $4^{\circ}$ constitucional.

Con lo anterior no se quiere decir que el enfoque del trabajo sea relativista, sino reconocer que a pesar de que se busca un objetivo de naturaleza cuantitativa, se trata de una construcción y que los resultados de tal estimación los determinan criterios y argumentos que se utilizan para definir lo digno y decoroso, criterios que se hacen explícitos y se presumen razonables pero no absolutos (siguiente apartado). Por otra parte, también se reconoce que un cálculo para todo el país supone un cierto grado de generalidad y que la magnitud del déficit es producto de valores seguramente distintos según la condición urbana o rural, regional y socioeconómica, análisis en los que ya se trabaja pero que resulta imposible incluirlos en este primer documento. De cualquier manera, la estimación del déficit nacional y según su tipo, como es el caso de este trabajo, resulta útil como un referente para el análisis de la política actual de vivienda. 


\subsection{Hacia una definición de lo digno y decoroso en la vivienda}

El concepto de vivienda incluye al menos cuatro componentes: a) protección o abrigo; $b$ ) funciones de la casa (descanso, sustento, reproducción y socialización); c) elementos decorativos que trascienden la sobrevivencia y la existencia y actúan como indicador de relaciones y conciencia social; y $d$ ) el acto de consumo que supone hablar de mercados, créditos, salarios, etc. (Ennals y Holdsworth 1998: 4). El conjunto de estos componentes lleva a una mezcla compleja de atributos que se insertan en una realidad aún más compleja que afecta el concepto a través de factores de muy diversa índole, como el cultural, los cambios en las necesidades sociales, las tradiciones, la ideología y el hábitat. El resultado de todo esto es que el concepto de vivienda digna y decorosa resulta por demás relativo. A continuación se hace un breve análisis de los principales factores que determinan la relatividad de lo que sería una vivienda adecuada.

En primer lugar, el componente cultural, entendiendo la cultura como expresión máxima de la adaptación del hombre al medio. En este sentido, la vivienda, la alimentación, el vestido, entre otros, son respuestas culturales y productos de las propias exigencias del medio (necesidades), de las posibilidades o recursos que éste ofrece y de las capacidades de la sociedad para habilitar soluciones, por lo que pueden ser muy diversas y siempre relativas a las condiciones mencionadas, por lo que una vivienda adecuada tendría que definirse en términos de condiciones del medio, de los recursos y de la tecnología.

A partir de lo anterior surge una posible reflexión: si los recursos disponibles son limitados y en consecuencia también la solución de vivienda, ¿debería entonces considerarse esa vivienda como adecuada, pues responde a la situación de requerimientos-recursos-tecnología existente? La respuesta sería sí, sólo a nivel individual. Pero si en una sociedad se cuenta con los recursos y las tecnologías para ofrecer una mejor condición de vivienda y por problemas de distribución de los satisfactores, una parte de la sociedad sólo puede acceder a viviendas que están debajo del estándar necesidad-recursos-tecnología, éstas deben considerarse inadecuadas, lo que implica que la vivienda adecuada o digna y decorosa no es independiente de la realidad social y generalmente está condicionada por la distribución de la riqueza; lo que nos lleva a mejor hablar de un componente sociocultural. 
Un segundo elemento de relatividad son las cambiantes condiciones de las necesidades sociales, lo que en un momento puede considerarse una necesidad social casi imprescindible, en otro pudo haber sido un lujo, y en otro ni siquiera se consideró como una posibilidad. Al respecto habría muchos ejemplos: la calefacción en regiones muy frías, el agua corriente en el interior de las viviendas, los sistemas sanitarios en la mayor parte de la sociedad contemporánea, etc. De manera que la idea de lo adecuado se va modificando a lo largo del tiempo.

El tercer elemento es el de las tradiciones, que imprimen ciertos rasgos a la vivienda y aunque no tengan una aplicación práctica, pueden ser profundamente valoradas por una sociedad o simplemente conservadas porque así son las cosas (casas).

También se debe considerar la ideología en muchos sentidos, pero sobre todo la concepción que imponen los grupos de poder en términos públicos y legales de lo que es una vivienda adecuada y que suele manifestarse a través del discurso. De esta manera hay una visión oficial de la vivienda adecuada, generalmente vaga y ambigua, pero que resulta útil para minimizar la problemática, para exaltar los avances o para favorecer ciertos intereses. Por ejemplo, en la actual política de vivienda en México no se considera como un aspecto relevante de lo adecuado la localización de la misma, seguramente como resultado de la propia incapacidad de la política federal en este aspecto para diseñar soluciones que liberen suelo bien ubicado. Irma Romero (2005: 43 y ss) hace una revisión interesante de las variaciones del discurso oficial en México, en el que se demuestra la enorme variación en las concepciones de lo que debe ser la vivienda.

La relatividad de la idea de una vivienda digna y decorosa se hace aún más compleja por la naturaleza inamovible del bien vivienda, lo que la lleva a asumir todas las características del entorno, configurando lo que en conjunto se conoce como hábitat. Esto lleva a que la vivienda puede tener por sí misma características satisfactorias pero también es posible que tenga una localización con enormes deficiencias en cuanto acceso al sitio de trabajo, los servicios, la recreación y, en general, la vida social, que por lo menos se traduce en un mayor costo de transporte, con lo que se disimula el verdadero costo de las viviendas que los desarrolladores transfieren como costos de transporte a los usuarios en el futuro y cobran por anticipado a través de la apropiación de renta del suelo, lo que ha sido muy común en el caso de viviendas económicas y de interés social en los últimos años. 
El no contar con una ubicación que permita acceder al lugar de trabajo, a los servicios y a la interacción social implica no tener una vivienda adecuada, pero la definición de accesibilidad es también relativa, cambiante, cultural y subjetiva.

Finalmente, la valoración de los elementos anteriores es por demás subjetiva, así que no es posible tener una definición común y fija de lo que es una vivienda adecuada, necesariamente se requiere construir de manera clara y explícita el concepto en un contexto sociocultural determinado, que es lo que presentamos a continuación.

\subsection{Propuesta metodológica}

En el contexto antes expuesto se plantea que la definición de lo digno y adecuado está sujeta al ámbito sociocultural y a la ideología del momento, y así, a lo que en el aspecto social es una solución aceptable para México. Metodológicamente sería deseable un análisis de cómo los diferentes sectores de la sociedad perciben lo que sería una solución adecuada, sin embargo, se trata de una aproximación muy compleja y costosa desde el punto de vista metodológico y aunque existen algunas experiencias al respecto, están lejos de ofrecer un visión acabada del tema. ${ }^{2}$

La alternativa que aquí se propone es el uso de los indicadores de la muestra del XII Censo General de Población y Vivienda 2000, que por primera vez está disponible en México. Esta aproximación metodológica de carácter estadístico imprime una condicionante más a lo que se determine como digno y decoroso, y se refiere a la disponibilidad de los indicadores. Aunque la muestra censal es una excelente fuente de información que ofrece 52 indicadores para la base de vivienda constituida por más de dos millones de registros y 81 indicadores para la base de personas con casi 10 millones de registros, hay aspectos que no es posible abordar. Para evitar una sobreestimación del déficit se propone una aproximación en dos grandes vertientes, en primer lugar se identificarán las necesidades de vivienda nueva, el déficit cuantitativo, en dos posibles situaciones: a) la vivienda para familias sin techo, compuestas por las extensiones de parentesco y los hogares extra; y $b$ ) viviendas que se deben reemplazar porque no son alojamientos residenciales, porque son cuartos redondos que

\footnotetext{
${ }^{2}$ Es justo reconocer los trabajos de J. Villavicencio et al. (2000); M. T. Esquivel (2005); J. Cervantes y E. Oliver (2005); E. Maya y J. F. Cervantes (2005); Cidoc y sHF (2006) y S. Mercado et al. (1995).
} 
no cuentan con servicios de baño y cocina, o porque son viviendas cuya edad ha superado la duración máxima de los materiales con que están construidas. La segunda gran vertiente es la identificación de viviendas con algún tipo de problema, que no requieren ser reemplazadas pero que tampoco pueden considerarse adecuadas, ya sea por problemas de calidad: $a$ ) su espacio es insuficiente para el tamaño de la familia; $b$ ) carecen de servicios básicos de agua, electricidad o drenaje; y c) las condiciones físicas no ofrecen la protección requerida; o por otro tipo de problemas como la inseguridad jurídica en la forma de ocupación de la vivienda y la mala localización que aumenta significativamente los costos de residencia.

Existen otras dimensiones que pueden hacer que la vivienda sea inadecuada, como las condiciones de salubridad e higiene -ventilación, iluminación, etc.- o la inseguridad estructural del inmueble; sin embargo, no se cuenta con indicadores para identificar las unidades que presentan estos problemas.

Esta aproximación metodológica en la que al universo se le van restando las unidades que de manera clara y bien fundada no cumplen con las condiciones para tomarse como una vivienda adecuada, garantiza que no se puede sobreestimar el problema; es decir, es posible tener certidumbre de que el déficit habitacional del país es, por lo menos, el que se estima, y que con toda seguridad algunas viviendas que se aceptaron como adecuadas, en realidad no lo son porque no cumplen con las dimensiones para las que no se contó con indicadores.

La muestra censal permite una aproximación muy fina a la situación de la vivienda ya que permite identificar las condiciones de las habitaciones y vincularlas con sus ocupantes. En la información agregada, como la censal, no es posible establecer la concurrencia de carencias en la vivienda, se puede saber la proporción de las que no cuentan con agua potable y energía eléctrica, o la proporción de las sobreocupadas, pero no es posible determinar cuántas de las que no tienen agua, además, tampoco cuentan con energía eléctrica y además tienen problemas de sobreocupación.

Para realizar la estimación se utilizaron varios programas de apoyo como Excel, sPSs y Access, sobre todo para preparar las bases de datos y para el manejo y presentación de los resultados, pero la base del procesamiento fue el lenguaje de programación del Mathlab. 


\section{Determinación del rezago cuantitativo}

Se considera rezago cuantitativo a la cantidad de viviendas nuevas que se requerían cuando se levantó la muestra censal. Este déficit no incluye las necesidades que se van generando en el tiempo como resultado de la formación de nuevas familias, tema que se trata al final de este trabajo. Así, el déficit cuantitativo es el número de viviendas que se requieren en un momento dado para satisfacer las demandas de la población.

Como se señaló, la necesidad de nuevas viviendas tiene tres dimensiones: las familias que no tienen una casa; las familias que ocupan un cuarto redondo, y las familias que habitan un espacio que ni siquiera se puede definir como vivienda.

La primera dimensión está constituida por las extensiones (ampliaciones) familiares y los hogares extra. En los términos censales de México, el concepto hogar se refiere al conjunto de personas que habitan una vivienda y que comparten un gasto, que en términos internacionales se denomina unidad de gasto (spending units). Esta idea de hogar se utiliza casi como sinónimo de familia civil, aunque en sentido estricto no lo es, y se clasifica de acuerdo con su composición en hogares nucleares, formados por uno o los dos padres con o sin hijos; hogares ampliados, en los que además del hogar nuclear se presentan otros familiares; hogares compuestos, donde hay personas que no son familiares y cohabitan con el hogar nuclear; hogares de corresidentes, que son grupos que cohabitan y comparten el gasto pero no tienen lazos familiares; y hogares unipersonales. Es decir, en cada vivienda habrá un hogar con alguno de estos formatos, pero además pueden presentarse hogares extra: grupos que comparten el gasto y cohabitan la vivienda con el hogar número uno. Los hogares extra se deben considerar claramente como parte del déficit de vivienda, ya que son familias independientes en lo económico pero que necesitan ocupar la vivienda de otra familia.

La necesidad de vivienda para el caso de las extensiones familiares no es tan evidente como para los hogares extra, pues en algunos casos la familia extendida es resultado de un problema de acceso a la vivienda y por tanto deben ser considerados como deficitarios; pero en otros casos, la cohabitación puede ser producto de otras lógicas como el cuidado de familiares. Como se dijo antes, el censo mexicano no identifica la estructura de las familias civiles, sólo es posible conocer el total de personas que forman parte de la extensión familiar y las relaciones de paren- 
tesco entre sus miembros así como al jefe de familia, pero no permite establecer cuántos miembros de la extensión familiar constituyen por sí mismos una familia que representaría una unidad de déficit de vivienda, por lo que es necesario analizar cada una de las relaciones de parentesco e imputar las posibles familias, así, si en la extensión familiar aparece un hijo de 30 años casado y una nuera de 25 años casada y dos nietos de 1 y 3 años, es posible asumir que constituyen una familia. Todas las relaciones plausibles se imputaron como una familia y como una unidad deficitaria, de manera que la insuficiencia puede estar subestimada porque quizás haya más unidades de déficit que las calculadas en este estudio, pero no menos.

Se consideraron como extensiones familiares aceptables que no generan necesidad de vivienda, y por tanto déficit, a los hijos solteros hasta la edad de 25 años o mayores que sufren alguna incapacidad. Estimamos que en el caso de los primeros, podrían ser independientes y están en edad de ejercer vida profesional, por lo que es posible que ya demanden una vivienda, además, el Instituto Mexicano del Seguro Social (IMSS) otorga pensión a huérfanos hasta los 25 años, por lo que es un límite conservador. De igual manera, se aceptaron como extensión familiar no deficitaria a los padres y ancestros mayores de 65 años, o de cualquier edad, cuando tienen alguna discapacidad; los menores de esta edad deberían tener acceso a una vivienda exclusiva. También fueron aceptados todos los familiares huérfanos o que no cohabitan con sus padres. Por el contrario, se consideraron extensiones familiares deficitarias a los hijos no solteros de cualquier edad y a otros parientes y no parientes.

La primera dimensión de déficit está compuesta por los hogares extra y las ampliaciones o extensiones familiares imputadas en unidades de demanda (familias sin vivienda) a partir de las relaciones de parentesco con el jefe del hogar.

Para la muestra censal del año 2000, en el país había 22'639,808 hogares (unidades de gasto, cuadro 1), de las cuales $96.5 \%(21$ '857,601) contaban con vivienda, mientras $3.5 \%$ era una familia extra que habitaba en la vivienda de otro hogar (782,207 casos). Por otra parte, había 7’440,791 familias ampliadas (incluye también hogares no familiares como los compuestos y corresidentes) en las que se puede encontrar al menos una persona o una familia que representan una unidad que requiere vivienda o demanda no efectiva; con lo que la necesidad real de una casa es mucho mayor que la reconocida oficialmente. 
Una posible explicación es que las extensiones familiares se suelen considerar como parte de la familia por el hecho de que no cuentan con un presupuesto propio, pero también se podría decir que son familias o personas con una situación económica difícil, incapaces de autonomía financiera y, con mayor razón, de independencia residencial.

\section{Cuadro 1}

\section{Distribución de hogares por composición a nivel nacional}

\begin{tabular}{|c|c|c|c|c|c|}
\hline \multirow[t]{2}{*}{ Tipo de hogar } & \multicolumn{2}{|c|}{$\begin{array}{c}\text { Con vivienda } \\
\text { (hogares } 1 \text { de la vivienda) }\end{array}$} & \multicolumn{2}{|c|}{$\begin{array}{c}\text { Sin vivienda } \\
\text { (hogares extra) }\end{array}$} & \multirow[t]{2}{*}{ Total } \\
\hline & Solos & $\begin{array}{l}\text { Compartiendo } \\
\text { (con extensión) }\end{array}$ & Solos & $\begin{array}{l}\text { Compartiendo } \\
\text { (con extensión) }\end{array}$ & \\
\hline & $2 ’ 325,640$ & $1^{\prime} 000,800$ & & 12,522 & \\
\hline Padres sol &, 111 & & & & \\
\hline Nuclear c/3 hijos & 4'535,801 & 1'139, & & & $5 ' 784,500$ \\
\hline Nuclear s/hijos & $1^{\prime} 636,413$ & 1'398,5 & 90,788 & 19,6 & $3 ' 145,380$ \\
\hline Personas solas & 1'386,969 & $1^{\prime} 758,747$ & 85,864 & 71,467 & 3'303,047 \\
\hline Total & $14,565,272$ & 7’292,329 & 633,745 & 148,462 & $22^{\prime} 639,808$ \\
\hline Nuclear c/2 hijos & $3 ’ 289,338$ & 867,797 & 130,577 & 9,685 & 4'297,397 \\
\hline
\end{tabular}

Fuente: Cálculos propios con base en la muestra censal (2002).

En esas casi siete millones y medio de extensiones familiares (y no familiares) se encontraban 20'197,709 personas de las cuales 5'572,747 (cuadro 3) justifican su presencia en la vivienda y no se deben considerar como una necesidad no satisfecha de habitación, ya sea porque son ancestros mayores de 65 años o discapacitados, o porque son menores sin presencia de padres en el hogar (3'291, 647) o bien, son sirvientes cuyos familiares están en situación de edad o discapacidad que los hacen dependientes.

Por otra parte, hay 14'624,962 de personas que no se justifica su presencia en las viviendas: 797,392 no constituyen familias y podrían ser inquilinos de ese hogar, pero el resto se agrupa en por lo menos 7’397,947 familias, más de 80\%, derivadas de los hijos casados que por su edad y situación civil deberían considerarse independientes.

El resultado es que se requieren poco más de ocho millones de viviendas para satisfacer a las familias que viven como extensión de otras y a los individuos que por su edad y condición deberían tener la posibilidad de acceder a una vivienda individual. Mientras la necesidad derivada de los hogares extra es obvia -y quizá por eso se reconoce ampliamente y también porque su 
Cuadro 2

Personas y familias según ubicación en la familia

\begin{tabular}{lrr}
\hline & Personas & \multicolumn{1}{c}{ Familias } \\
\hline Total & $97,014,475$ & $30,037,755$ \\
En la parte nuclear* & $76,816,766$ & $22,639,808$ \\
En la parte extendida** & $20,197,709$ & $7,397,947$ \\
\hline
\end{tabular}

"Incluye los hogares unipersonales.

**Incluye hogares compuestos y de coresidentes.

Fuente: Cálculos propios con base en la muestra censal (2002).

número no es tan significativo-, el problema de las extensiones familiares suele ignorarse o verse como algo normal.

En México, 22\% de la población forma parte de una extensión del hogar o de un hogar extra y 33\% -es decir, una de cada tres- de las viviendas tiene algún tipo de extensión. Aunque parece un dato alto, en realidad es bastante esperable si, por ejemplo, tomamos en cuenta que en Estados Unidos este porcentaje alcanza 26\% (Koebel y Murria, 1999: 138).

\section{Cuadro 3}

Distribución de personas en las extensiones según su condición

\begin{tabular}{|c|c|c|}
\hline Condición & Personas & Familias \\
\hline $\begin{array}{l}\text { Ancestros y menores sin presencia de padre } \\
\text { en el hogar }\end{array}$ & $3,291,647$ & No aplica \\
\hline Sirvientes y otros parientes dependientes* & $2,281,100$ & No aplica \\
\hline $\begin{array}{l}\text { Personas que forman parte de un familia } \\
\text { (imputadas) }\end{array}$ & $13,827,570$ & $7,397,947$ \\
\hline $\begin{array}{l}\text { Otras personas parientes y no parientes } \\
\text { que podrían ser independientes } \\
\text { Total de personas en extensiones }\end{array}$ & $\begin{array}{r}797,392 \\
20,197,709\end{array}$ & No aplica \\
\hline
\end{tabular}

"Los otros parientes dependientes incluye poco más de 128,000 cónyuges secundarios, es decir, la suma de las personas que se declararon esposa(o) del jefe de familia cuando fue más de una; la suma incluye a partir de la segunda declaración.

Fuente: Cálculos propios con base en la muestra censal (2002).

Todavía faltaría agregar las viviendas que se deben reemplazar totalmente porque no tienen opción de adecuarse a través de mejoras. Una buena parte de éstas no sólo carecen de las características para que se les considere una habitación mínima, sino que la mayoría de las veces su situación jurídica es irregular, pues se trata de asentamientos en zonas federales o con problemas de tenencia, o bien, son arrendamientos sin seguridad jurídica. 
Este grupo de viviendas se compone de alojamientos inadecuados entre los que se incluyen: cuartos de azotea, locales no construidos para vivienda, vivienda móvil (en la mayoría de los casos se trata de carros de ferrocarril) y refugios y lugares no especificados. Todas ellas definiciones directas del propio censo y alcanzan 713,093 unidades. Por otro lado están las que se conocen como cuartos redondos, es decir, que no cuentan con baño ni cocina, lo que limita algunas de las funciones más elementales de un espacio para habitación (534,423 unidades). Finalmente están las viviendas caducas -construidas con materiales inadecuados-, entre las que se contaron aquéllas fabricadas con materiales de desecho o con láminas de cartón, asbesto o metálica, también se consideraron las casas cuya edad ya superó el tiempo medio de vida útil de los materiales con que están construidas, según los criterios establecidos por Coplamar (1982: 184), basados a su vez en Barrientos (1972), estos dos últimos conceptos suman 723,212 casos.

De esta manera, el rezago cuantitativo era de 8'977,546 considerando extensiones familiares $(8,195,339)$ y hogares extra (782,207), más 1'970,728 unidades a reemplazar (cuadro 4) llegando a un total de 10'948.274. En este caso no se incluye a aquéllos que habitan en la calle, pues al no tener un lugar de residencia habitual no aparecen en los censos de población y vivienda, lo que agregaría otros pocos miles.

\section{Cuadro 4}

Total de viviendas a reemplazar

\begin{tabular}{lr}
\hline Alojamientos inadecuados & 713,093 \\
Cuartos redondos & 534,423 \\
Viviendas caducas & 723,212 \\
Total & $1 ' 970,728$ \\
\hline
\end{tabular}

Fuente: Cálculos propios con base en la muestra censal (2002).

\section{Determinación del rezago por calidad}

La vivienda debe brindar protección y permitir el sano desarrollo de sus ocupantes. La primera se refiere al resguardo de sus ocupantes de las condiciones del medio como el frío, el viento, el calor, la lluvia, la nieve, e incluso, de animales y de otros miembros de la sociedad; además de ofrecer un ambiente higiénico. Algunas viviendas que no cumplen estas funciones ya se descar- 
taron en el apartado anterior, otras cuyas deficiencias se pueden resolver se cuentan aquí evaluando los espacios, los servicios y el tipo de materiales de construcción para conocer su capacidad de protección. Por supuesto hay muchos otros aspectos que convergen en el resguardo de una vivienda y que depende de la tecnología, el diseño, su mantenimiento, entre otros, pero como se mencionó, no hay información disponible para hacer una valoración de ellos, lo que en todo caso aumentaría aún más el déficit.

La idea de sano desarrollo de sus ocupantes se vuelve más compleja en la medida que a la salud se agregan los aspectos psicológicos y sociales. ¿Cómo definir exactamente los requerimientos de la vivienda para que esto se cumpla? Se utilizan tres grandes dimensiones para estimar los problemas de calidad: en primer lugar se evalúan las condiciones de tamaño, tanto en relación con su nivel de ocupación, como en la diferenciación del espacio al interior de las viviendas; después se analiza la disponibilidad de servicios de agua, drenaje, electricidad y combustible para cocinar; y por último, se mide la protección en términos físicos, específicamente considerando los materiales de pisos y techos.

Por supuesto hay sobreposición entre los aspectos de calidad incluidos, es decir, hay viviendas que presentan más de un problema de calidad, por lo que el conteo independiente de cada variable llevaría a una enorme sobreestimación. Para evitar esto, primero se calcularon la viviendas que tenían problemas de espacio porque se consideró que es el más complejo de analizar, lo que implica que algunas viviendas con este problema además pueden tener otros en el resto de los aspectos estudiados; del universo restante se contaron las que tenían dificultades con los servicios, que seguro ya no tendrían problemas de espacio pero posiblemente sí con el resto de las variables; entre las viviendas restantes se contaron las que tienen algunas carencias de protección. Con esto se valoran los problemas de calidad, pero en el apartado siguiente se consideran otro tipo de situaciones que hacen que una vivienda no sea digna y decorosa, como la inseguridad jurídica o la falta de accesibilidad.

\subsection{Viviendas con problemas de espacio}

El espacio que debe ofrecer una vivienda para ser digna y decorosa es una de las dimensiones más relativas entre los atributos de una casa. No es fácil establecer una definición conceptual válida, de hecho, se trataría de cualquier forma de construcción 
conceptual con muchas implicaciones, lo que a final de cuentas se hace en este trabajo. Lo que sí es cierto, es que en la política actual de vivienda en México hay una fuerte tendencia a validar viviendas mínimas, menores a $55 \mathrm{~m}^{2}$ y que pueden llegar a ser tan pequeñas como $36 \mathrm{~m}^{2}$. En el caso de las que promueve el Instituto del Fondo Nacional de la Vivienda para los Trabajadores (Infonavit), en los últimos años más de $50 \%$ eran menores a $55 \mathrm{~m}^{2}$; en el caso del Fondo de Operación y Financiamiento Bancario a la Vivienda-Sociedad Hipotecaria Federal (Fovi-SHF), en este rango cayeron 38.8\% de las unidades y del Fondo de la Vivienda del Instituto de Seguridad y Servicios Sociales de los Trabajadores del Estado (Fovissste), 29.3\% (Romero, 2005: 324-327). Al respecto, vale revisar la experiencia internacional donde no son pocos los países -como Japón, Singapur, Francia y Austria, entre otros- que en ciertas etapas favorecieron la construcción de viviendas muy pequeñas $\left(45 \mathrm{~m}^{2}\right)$, pero casi sin excepción han modificado sus criterios hacia superficies mínimas que van de 75 a $100 \mathrm{~m}^{2}$, lo que en ocasiones implicó la sustitución física de las viviendas pequeñas (Chi Ong, 2002; Cortés, 2001). Esto no sólo provocó problemas de rechazo, con base en la experiencia chilena, la Organización Mundial de la Salud (OMS) informó de problemas de salud mental asociados con ocupaciones de viviendas menores a $60 \mathrm{~m}^{2}$ (El Mercurio, 2002), resultados que también se reportaron para México (Poblett, 2002). Se trata de experiencias que demuestran lo equivocado de estas políticas y el mayor costo indirecto en el mediano plazo. Sin embargo, la política mexicana mostró una transformación opuesta, de viviendas mayores a $100 \mathrm{~m}^{2}$, como en el multifamiliar Benito Juárez (1947) y Tlatelolco (1964) (Winfield, 2000: 395), a las viviendas de $36 \mathrm{~m}^{2}$ de la actualidad, que obliga a que muchas de las necesidades de sus ocupantes se resuelvan en la calle, como la socialización y la recreación.

Como se afirmó, se trata de un problema complejo por su relativismo (Friedman y Cammalleri, 1994; Roberge, 1996; Teasdale, 1996; Verret, 1999) que debe definirse en un contexto sociocultural específico. Además, la limitación en la evaluación del problema es aún mayor por la falta de indicadores -como la superficie en $\mathrm{m}^{2}$ - pues, en general, los censos nacionales informan el número de cuartos, el de dormitorios, la existencia de baño y cocina y el número de ocupantes de la vivienda, información a partir de la cual sólo se puede inferir la dificultad de espacio. 
Para conocer este tipo de problemas, lo primero fue restar del grupo de ocupantes a todos los individuos que formaban parte de los hogares extra y de las extensiones familiares, pues la problemática que generan se evaluó en los apartados anteriores, de otra forma habría una doble contabilización. Posteriormente se concibió el problema de espacio en dos vertientes: como una situación de insuficiencia (hacinamiento), para lo que se usó el criterio de la Organización de Naciones Unidas (ONU-CEPAL 2002). que considera aceptable hasta 2.5 personas por habitación (Michel, 1992: 46); y como un asunto de diferenciación, para lo que se tomó en cuenta la existencia de baño y cocina en la vivienda.

El hacinamiento se evaluó sólo en las viviendas con dos o más cuartos y con cocina y baño exclusivos. El que se tenga un solo cuarto, provoca que el dormitorio no sea exclusivo -situación que se mide más adelante-, y lo mismo sucede con las viviendas sin baño y cocina exclusivas. De esta manera se contabilizaron como viviendas sobreocupadas aquéllas aparentemente en buenas condiciones y con espacios diferenciados, al menos un dormitorio y estancia-comedor, baño y cocina exclusivos, pero que su promedio de ocupantes por dormitorios es mayor a 2.5, es decir, las de un dormitorio con tres o más ocupantes, dos dormitorios con seis o más ocupantes, tres dormitorios con ocho o más, y así sucesivamente. El resultado de este conteo fue de 2'183,733 viviendas, de las cuales dos terceras partes son de un dormitorio y $94 \%$ de uno o dos dormitorios, lo que significa que el problema está fuertemente asociado con el tamaño de la vivienda (cuadro 5).

\section{Cuadro 5}

Viviendas con cuartos insuficientes para sus ocupantes

\begin{tabular}{lccrcc}
\hline \multicolumn{1}{c}{ Concepto } & $\begin{array}{c}\text { Número de } \\
\text { dormitorios }\end{array}$ & $\begin{array}{c}\text { Número de } \\
\text { habitantes } \\
\text { mayor a }\end{array}$ & $\begin{array}{c}\text { Número de } \\
\text { viviendas }\end{array}$ & $\begin{array}{c}\text { Porcentaje } \\
\text { respecto } \\
\text { del total } \\
\text { nacional }\end{array}$ & $\begin{array}{c}\text { Porcentaje } \\
\text { respecto } \\
\text { del } \\
\text { concepto }\end{array}$ \\
\hline Cuartos insuficientes & 1 & 2 & $1,473,836$ & 6.74 & 67.5 \\
para sus habitantes & 2 & 5 & 575,307 & 2.63 & 26.4 \\
& 3 & 10 & 125,546 & 0.57 & 5.8 \\
& 4 & 12 & 8,066 & 0.04 & 0.4 \\
Total & 5 o más & 14 & 978 & 0.01 & 0 \\
\hline
\end{tabular}

Fuente: Cálculos propios con base en la muestra censal (2002). 
El siguiente grupo de conceptos se refiere a la diferenciación de espacios, contabilizando las viviendas sin cocina y baño exclusivos y sin dormitorios. En los casos de la cocina y el baño significa que se usan además para otra función, principalmente como dormitorios; en cuanto al problema de dormitorio quiere decir que esta función se comparte con otras como la de estar o comer. Las viviendas que no tienen cocina exclusiva alcanzan 1'853,502, mientras que las casas que no tienen baño o cuyo uso no es exclusivo son 1'657,010 y sin baño ni cocina exclusivas, 425,654 (cuadro 6). Finalmente, las unidades con problemas de dormitorio son 1'093,149 casos más.

\section{Total de viviendas con problemas de espacio}

\begin{tabular}{|c|c|c|c|}
\hline \begin{tabular}{l}
\multicolumn{1}{c}{ Concepto } \\
Sobreocupación \\
(hab./dormitorios) \\
Diferenciación de \\
espacios
\end{tabular} & & Viviendas & Porcentaje \\
\hline \multirow{9}{*}{$\begin{array}{l}\text { Sobreocupación } \\
\text { (hab./dormitorios) } \\
\text { Diferenciación de } \\
\text { espacios }\end{array}$} & & $2,183,733$ & 9.99 \\
\hline & $\begin{array}{l}\text { Sin cocina } \\
\text { exclusiva }\end{array}$ & 1'853,502 & 8.48 \\
\hline & Sin cocina & 526,932 & \\
\hline & No exclusiva & $1^{\prime} 326,570$ & \\
\hline & $\begin{array}{l}\text { Sin baño } \\
\text { exclusivo }\end{array}$ & $1^{\prime} 657,010$ & 7.58 \\
\hline & Sin baño & $1 ’ 200,621$ & \\
\hline & No exclusivo & 456,389 & \\
\hline & $\begin{array}{l}\text { Sin cocina ni } \\
\text { baño exclusivos }\end{array}$ & 425,654 & 1.95 \\
\hline & Sin dormitorios & 1'093,149 & 5 \\
\hline Total de viviendas & & $7 ’ 213,048$ & 33 \\
\hline
\end{tabular}

Fuente: Cálculos propios con base en la muestra censal (2002).

Por otra parte, el número de viviendas que sólo tienen problemas de espacio, esto es, que no presentan problemas de servicios ni de protección, es de 2’292,275³ (cuadro 10), número muy alto

\footnotetext{
${ }^{3}$ El total de viviendas que sólo tiene problema de espacio resulta de restar al total de viviendas con problemas de espacio las que además de esta dificultad, tienen otras. Es muy probable que las viviendas presenten más de un problema, por lo que habrá que distinguir entre la cantidad de viviendas que tienen X problema y quizá algún otro, y el total de las que sólo tienen ese $X$ problema. Más adelante se presenta la sobreposición de los distintos universos (gráfica I y cuadro 10) donde se puede distinguir el número de viviendas según el o los problemas que presenta. El total de viviendas que sólo tienen problema de espacio resulta de restar al total de viviendas con esta dificultad, aquéllas que además de tener problemas de espacio, tienen otros.
} 
si se compara con las otras dimensiones del déficit cualitativo, lo que pone al espacio como la principal dificultad en cuestiones de calidad, sin considerar el agravamiento de éste cuando se incluye a las familias extendidas, por lo que no sería exagerado decir que México es un país hacinado.

El concepto de rezago se refiere a la falta de viviendas, las que requieren las familias que no cuentan con un lugar exclusivo para vivir y tienen que usar la casa de otra familia, y a las viviendas que no se pueden considerar como tales aunque forman parte del stock y se utilizan como viviendas, pero una tercera parte del total nacional registra problemas por limitaciones en los espacios.

\subsection{Viviendas con problemas de servicios}

La siguiente dimensión del rezago o déficit cualitativo se refiere a los servicios y es importante señalar que si bien este grupo de viviendas ofrece un servicio de habitación a sus usuarios, se considera parte del déficit porque no cubre las condiciones mínimas de uso que se definieron antes, es decir, el servicio que ofrecen es deficitario. Se consideraron cuatro dimensiones: disponibilidad de agua potable, drenaje sanitario, electricidad y combustible. En realidad, la condición de las viviendas respecto de estos servicios no es dicotómica, en el sentido de que cuentan o no con ellos. Hay muchas situaciones intermedias sobre las que se debe tomar posición para establecer lo que se considera deficitario; entre más exigente se sea en relación con el servicio para llamarlo satisfactorio, mayor será la cantidad de viviendas que no lo cumplan y mayor será el déficit.

En el tema del agua, se calificó como satisfactorio si el servicio se encuentra dentro del predio, aunque no se cuente con un sistema de distribución al interior del inmueble y tampoco se consideró indispensable tener agua todos los días, se tomó como aceptable si la reciben sólo algunos días o durante una parte del día. Para el drenaje creímos que es razonable si se tiene conexión a la red pública o a una fosa séptica, a pesar de las deficiencias que pudieran tener éstas. Por su parte, se juzgó suficiente disponer del servicio de energía eléctrica, aunque reconocemos también que éste puede ser de muy mala calidad o no continuo. Finalmente, como combustibles apropiados para cocinar en una vivienda digna y decorosa se incluyeron el gas y la electricidad, ya que los demás son poco higiénicos y peligrosos. 
Parece claro que las carencias de estos servicios no son excluyentes, lo que significa que hay viviendas en las que pueden faltar uno, dos, tres o los cuatro, de manera que si se hiciera la cuenta por separado, habría sobreposición. De hecho, se identificaron 15 combinaciones no sobrepuestas de deficiencias de servicios que se presentan en el cuadro 7.

El total de viviendas con algún tipo de problema de servicios fue de 6'136,868; sin embargo, buena parte de ellas tenía además la dificultad de espacio que ya fue cuantificado en la sección anterior (el número de viviendas con problemas de espacio fue de 7’213,048), por lo que la cantidad que se agrega al déficit es sólo el de las unidades con problemas de servicios pero que no tienen problemas de espacio, de lo que resultó un monto de 2’149,604 unidades más. Finalmente, las viviendas que sólo tienen problema de servicios pero ninguno de otro tipo (espacio, protección o seguridad) fue de 1’197,633.

Del cuadro 7 se desprende que el servicio más deficitario en el país es el drenaje, ya que la suma de las combinaciones que incluyen este servicio llega casi a 22\% del total nacional, en otras palabras, más de una de cada cinco viviendas no tiene ni siquiera acceso a una fosa séptica. La carencia de agua no es menos dramática ya que más de $10 \%$ de las viviendas no cuenta con el servicio en el predio. Si a lo anterior se agregan los más de siete millones de viviendas con problemas de espacio, más los varios millones del déficit cuantitativo, más los rubros que faltan por evaluar, se vislumbra un rezago mucho mayor del reconocido.

\subsection{Viviendas con problemas de protección}

Con los indicadores disponibles es difícil valorar las condiciones de protección que ofrecen las viviendas, pero es plausible pensar que si los techos son de lámina de cartón, metálica o de asbesto, o de materiales de desecho y los pisos son de tierra, la vivienda no ofrece la protección adecuada a sus ocupantes. Hay un total de 5'546,447 viviendas que registran problemas de protección por los materiales en pisos y/o techos, casi una cuarta parte del total nacional, pero como en los casos anteriores, muchas de ellas ya se contabilizaron entre las que tienen problemas de espacio y las que tienen deficiencias de servicios, por lo que la acumulación al déficit es de 1’017,822 unidades.

En el cuadro 8 se muestra la distribución de las viviendas con baja calidad, destacando los problemas de espacio, esto a pesar 


\section{Cuadro 7}

Viviendas con problemas de servicios según la combinación de problemas

\begin{tabular}{|c|c|c|c|c|}
\hline Deficiencia de & $\begin{array}{c}\text { Servicio } \\
y \text { otros }\end{array}$ & Porcentaje & $\begin{array}{c}\text { Porcentaje } \\
\text { del total } \\
\text { nacional }\end{array}$ & $\begin{array}{c}\text { Servicios y } \\
\text { otros pero } \\
\text { no espacio } \\
\text { (cuenta al } \\
\text { déficit) }\end{array}$ \\
\hline Agua & 655,082 & 10.67 & 3 & 370,833 \\
\hline Agua y drenaje & 498,908 & 8.13 & 2.28 & 170,617 \\
\hline Agua, drenaje y electricidad & 70,838 & 1.15 & & 17,209 \\
\hline Agua y electricidad & 24,941 & 0.41 & 0.11 & 11,466 \\
\hline Agua, electricidad y combustible & 39,308 & 0.64 & 0.1 & 10,686 \\
\hline Agua, drenaje y combustible & 793,922 & 12.94 & 3.63 & 169,650 \\
\hline Agua y combustible & 189,821 & 3.09 & 0.87 & 70,877 \\
\hline Drenaje & $1 ' 508,208$ & 24.5 & 6 & 681,860 \\
\hline Drenaje y electricidad & 39,973 & 0.65 & 0.18 & 9,311 \\
\hline Drenaje y combustible & $1^{\prime} 099,250$ & 17.91 & 5.03 & 280,966 \\
\hline $\begin{array}{l}\text { Drenaje, electricidad y } \\
\text { combustible }\end{array}$ & 171,491 & 2.79 & 0.78 & 27,002 \\
\hline Electricidad & 35,901 & 0.59 & & 17,072 \\
\hline Electricidad y combustible & 29,650 & 0.48 & 0.14 & 10,124 \\
\hline Combustible & 567,561 & 9.25 & 2.6 & 249,352 \\
\hline Todos (sin servicios) & 412,014 & 6.71 & 1.88 & 52,579 \\
\hline Totales & 6’136,868 & 99.99 & 28.06 & $2 ’ 149,604$ \\
\hline
\end{tabular}

Fuente: Cálculos propios con base en la muestra censal (2002).

de que en la cuenta no se consideraron las extensiones familiares ya que éstas se habían contabilizado para el déficit cuantitativo, lo que significa que en la realidad el problema de hacinamiento es mucho peor que el sugerido aquí en la cuenta del déficit, lo que fue necesario por cuestiones técnico-metodológicas.

Si tomamos en cuenta que 1'970,728 viviendas se deben reemplazar porque no es posible considerarlas como lugares habitables, se tiene que más de la mitad de las poco menos de 20 millones de viviendas restantes en el país tienen deficiencias serias de calidad.

Se debe insistir en la distinción entre el total de viviendas que tienen algún tipo de problema y la contribución que cada grupo hace a la contabilización del déficit. En este sentido, los resultados aceptan una doble lectura: la dimensión de cada uno de los problemas y la cuantificación del déficit. Si el orden en que fueron evaluados cada uno de los aspectos se modifica, no habría cambio en el total de viviendas con determinadas dificultades, 


\section{Cuadro 8}

Viviendas con problemas de calidad por combinación de problemas

\begin{tabular}{lr}
\hline \multicolumn{1}{c}{ Problemas } & \multicolumn{1}{c}{ Viviendas } \\
\hline Solo espacio & $2 ’ 292,275$ \\
Solo servicios & $1 ’ 197,633$ \\
Solo protección & $1^{\prime} 017,822$ \\
Espacio y servicios & $1^{\prime} 344,119$ \\
Espacio y protección & 933,509 \\
Servicios y protección & 951,971 \\
Espacio, servicios y protección & $2 ’ 643,145$ \\
Total & $10^{\prime} 380,474$ \\
\hline
\end{tabular}

Fuente: Cálculos propios con base en la muestra censal (2002).

\section{Cuadro 9}

Viviendas por carencia de servicios y contribución al déficit cualitativo

\begin{tabular}{lcc}
\hline Tipo de problema & Total de viviendas & Contribución al déficit \\
\hline Espacio & $7^{\prime} 213,048$ & $7^{\prime} 213,048$ \\
Servicios & $6^{\prime} 136,868$ & $2^{\prime} 149,604$ \\
Protección & $5^{\prime} 546,447$ & $1^{\prime} 017,822$ \\
Total & & $10^{\prime} 380,474$ \\
\hline
\end{tabular}

Fuente: Cálculos propios con base en la muestra censal (2002).

\section{Gráfica I}

Universo de viviendas con problemas de servicios

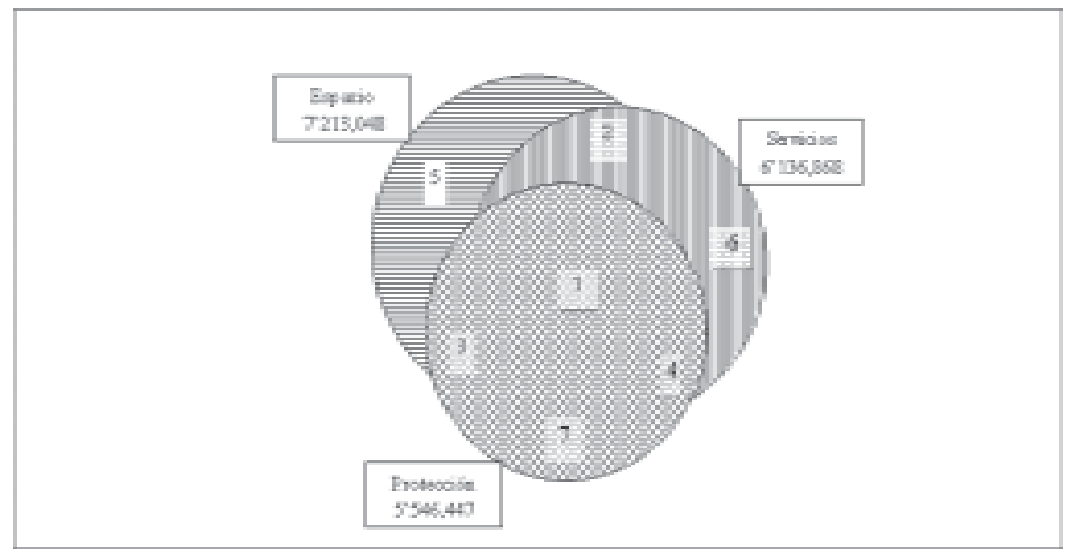

Fuente: Cálculos propios con base en la muestra censal (2002). 
pero sí serían diferentes las contribuciones de cada rubro a la medición del rezago, aunque la suma total de éste continuaría siendo de 10’380,474 unidades sólo por problemas de calidad.

En la gráfica I se representa la conformación de los universos de viviendas con problemas de servicios. La superficie de los círculos representa exactamente la proporción del déficit, pero las áreas de sobreposición son aproximadas. Los totales de viviendas de cada tipo de problema aparecen en la gráfica y, además, en el cuadro 10 se presentan las cantidades de unidades en cada situación o áreas de conjunción de los círculos.

Como se deduce del cuadro 10, la mayor parte de las viviendas con problemas de calidad (que representan la mitad de las viviendas reales de país) muestran los tres tipos de dificultades al mismo tiempo: espacio, servicios y protección, lo que es esperable teniendo en cuenta que se trata básicamente de un problema de pobreza. El segundo rubro más importante del universo es el de problemas exclusivamente de espacio, que como ya se explicó, por sí mismo era el elemento deficitario más importante de todos.

\section{Cuadro 10}

Universo de viviendas con problemas por tipo de servicio

\begin{tabular}{lrcc}
\hline Problemas & Viviendas & Porcentaje & $\begin{array}{c}\text { Área en la } \\
\text { gráfica }\end{array}$ \\
\hline Espacio, servicios y protección & $2^{\prime}$ '643,145 & 25 & 1 \\
Espacio y servicios & $1 ' 344,119$ & 13 & 2 \\
Espacio y protección & 933,509 & 9 & 3 \\
Servicios y protección & 951,971 & 9 & 4 \\
Sólo espacio & 2 '292,275 & 22 & 5 \\
Sólo servicios & 1 '’ 197,633 & 12 & 6 \\
Sólo protección & 1 '017,822 & 10 & 7 \\
Total & $10^{\prime} 380,474$ & 100 & \\
\hline
\end{tabular}

Fuente: Cálculos propios con base en la muestra censal (2002).

Después hay una diferencia importante con el tercer rubro que alcanza $13 \%$ de este conjunto de viviendas y se refiere al espacio y los servicios. La protección es, en cambio, el componente de calidad con menor contribución al déficit, de lo que se puede concluir que los problemas de vivienda en México son más de sobrepoblación y diferenciación de espacio y menos de calidad de las construcciones, lo que parece que contribuye a demostrar que la producción social de vivienda ha jugado un papel importante en el aprovisionamiento. 


\section{Otras limitaciones a la vivienda digna y decorosa}

Se valoraron dos aspectos más que no contribuyen al déficit cuantitativo pues son atributos de las viviendas existentes y tampoco representan en sí mismos una deficiencia de calidad, pero indudablemente son un problema social de la condición de la vivienda. Estos atributos son la seguridad jurídica que tiene la familia respecto de la vivienda que ocupa y el acceso al equipamiento.

\subsection{Viviendas como problemas de seguridad jurídica}

La muestra censal arroja dos preguntas sobre la tenencia de la vivienda: la primera es si ésta es propiedad de alguna de las persona que la habitan, en caso afirmativo se pregunta es si se está pagando, si está totalmente pagada o si se encuentra en otra situación; en caso negativo, se cuestiona si es rentada, prestada, la cuidan o está en otra situación.

Se consideró que si la vivienda es propiedad de alguno de sus ocupantes o la alquilan, no representa un problema, lo cual no necesariamente es cierto, pues gran parte del arrendamiento se da en condiciones de informalidad sin informar al fisco y sin certidumbre jurídica para quienes la ocupan, por lo que otra vez el problema en realidad podría ser mayor al que se estima aquí, pero se mantiene la actitud conservadora ante la medición del déficit.

De esta manera, sólo se juzgó como deficitarias a las viviendas que están prestadas o en otra situación, que son básicamente circunstancias de incertidumbre jurídica. El total de unidades que presentan este tipo de problemas es de 2'138,738, pero de ellas sólo 706,876 contribuyen al déficit, es decir, 33\% de las unidades no habían sido consideradas por algún otro problema. Con esto la acumulación al déficit llega a 11'087,350 viviendas.

Aquí cabe destacar un hecho importante, 33\% de viviendas que sólo tuvieron problema de seguridad jurídica representa el valor más alto entre las proporciones de problemas únicos. Las que sólo tuvieron dificultad de espacio fue 31.5\%, las de únicamente servicios fue $19.5 \%$ y las de sólo protección $18.3 \%$. Esto significa que la seguridad jurídica es el problema más independiente, es decir, que es más probable que se presente solo, seguido por el problema de espacio, ya que son aspectos que no están tan fuertemente vinculados con la situación de pobreza; en cambio servicios y protección muestran mayores asociaciones con 
los demás (menor independencia) por una mayor correlación con la pobreza.

Otro aspecto que se debe mencionar es que la pregunta del censo se refiere exclusivamente a la vivienda y no al suelo, de manera que las personas que construyeron su casa en situaciones de irregularidad (más de 60\% del aprovisionamiento de vivienda en el país), pueden responder que la vivienda es propia pero el suelo puede mantenerse en situación irregular.

\subsection{Viviendas con problemas de accesibilidad}

El último problema que se midió fue el de la accesibilidad de la vivienda, que es una forma de valorar las condiciones de localización. Al respecto debe establecerse que no basta una buena vivienda, se requiere que su articulación con el resto de las actividades satisfaga una serie de condiciones mínima de acceso al empleo, los servicios comerciales, educativos, de salud, de recreación y al conjunto de la sociedad. No es digna ni decorosa la vivienda cuya localización no permite a sus habitantes acceder a estos servicios en tiempos, costos y riesgos razonables.

Este aspecto se midió a partir de la situación de no asistencia de los niños a la escuela por quedar lejos. Por supuesto, el ir a la escuela no significa que ésta o que el conjunto de los requerimientos de accesibilidad de la familia sea satisfactorio. De hecho, la facilidad para asistir a la escuela es una de las dimensiones de acceso mejor satisfechas en la sociedad mexicana por la buena cobertura de la educación pública y por el gran esfuerzo que las familias están dispuestas a hacer para enviar a sus hijos a la escuela, por lo que no es raro que dediquen varias horas diarias de traslado, sobre todo en zonas rurales; además, este indicador mide la no asistencia a la primaria, que es el nivel educativo de mejor cobertura. El hecho es que se trata, por desgracia, del único indicador disponible, al tiempo que se habla de uno de los aspectos más relevantes en la calidad del hábitat. Es un hecho conocido que una buena dotación de servicios públicos resuelve muchos requerimientos que de otra forma se tendrían que remediar en el interior de las viviendas.

Por la metodología de exclusión de universos y por la debilidad del indicador disponible, el número de viviendas que se acumula al déficit habitacional como consecuencia de la falta de accesibilidad es sólo de 24,044. También es necesario apuntar que este tipo de problemas se debió multiplicar con la política de 
vivienda del gobierno actual, que en su afán por promover la producción de vivienda, lo que es encomiable, descuidó componentes importantes como la política de suelo, sostén de la producción de vivienda, lo que resulta en ubicaciones irracionales que representan un alto costo social por su efecto en la expansión urbana y en un gran costo para los ocupantes de esas viviendas, que terminan pagando la vivienda a través de los fuertes pagos de transporte.

Con lo que el déficit acumulado de viviendas que requieren mejoras en algún aspecto llega a 11'111,394. Mientras que el rezago cuantitativo, es decir, las casas nuevas que se necesitan son 10'948,274. Con esto se alcanza la impactante cantidad de 22'059,668, un número muy semejante al universo de viviendas en el país en el año 2000.

La lectura que se debe hacer es la siguiente: 50.08\% (11'111,394 de las 21'857,601 del total nacional) de las viviendas del país tienen alguna deficiencia cualitativa que es susceptible de ser resuelta, pero se requieren otros 10.948 millones de nuevas viviendas más para que cada familia cuente con una; de éstas, 1'970,728 son unidades que deben ser reemplazadas y 782,207 son hogares extra, el resto, casi ocho millones, se requieren para las extensiones familiares.

\section{Discusión y conclusiones}

A fines de los años ochenta y principios de los noventa, el dato de seis millones de viviendas era el referente común en los círculos oficiales. En la actualidad se habla de rezago habitacional para referirse al número de viviendas que por sus características de ocupación (hacinamiento) y por los componentes y materiales utilizados en la edificación (deterioro) no satisfacen un mínimo de bienestar para sus ocupantes (www.conafovi.gob.mx; Conafovi, DC, Rezago.pdf, s/f: 11). Existen dos tipos de rezago: el cuantitativo, que se refiere a necesidades de vivienda nueva para los hogares que no cuentan con una y para sustituir viviendas de mala calidad o que ya terminaron su vida útil; y el cualitativo, que supone acciones de ampliación y mejoramiento para resolver los problemas de calidad (ibidem). La propia Comisión Nacional de Fomento a la Vivienda (Conafovi) establece que los problemas de calidad se definen por materiales, dimensiones, ubicación geográfica, infraestructura básica y servicios (ibidem). 
Los resultados del rezago habitacional para el año 2000 fueron de 4'290,665 viviendas en total, de las cuales 1'810,930 son viviendas nuevas y 2'479,735 requieren acciones de mejoramiento (Conafovi, s/f, b). Según la Sedesol, 37.4\% de los hogares urbanos del país se encontraban en situación de pobreza patrimonial; teniendo en cuenta que en el campo ese porcentaje debe ser mucho más alto, concluimos que la pobreza patrimonial en el país debe superar por mucho $40 \%$, lo que puede involucrar a cerca de nueve millones de viviendas.

La diferencia con la estimación de Confovi (s/f a) se debe a que esta institución se basa exclusivamente en los datos del XII Censo General de Población y Vivienda 2000, lo que la obliga a realizar cálculos con muchas limitaciones por la naturaleza agregada de la información censal; además, dentro del déficit o rezago sólo consideran el hacinamiento que se compone de los hogares sin vivienda y de la sobreocupación de cuartos, lo que implica dos limitaciones serias: en primer lugar, las familias sin casa sí implican una necesidad de vivienda (y no necesariamente hacinamiento), pero no incluyen una estimación de las extensiones familiares, gran parte de las cuales también representan una necesidad de vivienda pero que no se consideran como hogar porque no tienen un manejo independiente de su presupuesto, lo que lleva a una enorme subestimación. Por otra parte, el cálculo de sobreocupación se basa en los cuartos (2.5 habitantes por cuarto), mientras en este trabajo se consideró usar exclusivamente dormitorio y se llevó a cabo una estimación no agregada, es decir, midiendo vivienda por vivienda. Finalmente, el rezago cualitativo lo consideran sólo en función del deterioro, en sentido estricto de la probabilidad del desgaste de las viviendas fijando esta probabilidad en función de la calidad de los materiales (ibidem: 13-18), mientras que en nuestra evaluación el deterioro consideró directamente la edad de las viviendas (disponibles en la muestra censal) y los materiales con que se construyeron, pero también incluimos como problema de rezago cualitativo la carencia de servicios, todo lo cual explica la diferencia con la estimación de la Conafovi.

El Centro de Investigación y Documentación de la Casa (Cidoc) (2004: 7), junto con el Joint Center for Housing Studies de la Universidad de Harvard, establece la necesidad de reemplazar tres millones de viviendas, 5.1 millones requerían mejoras moderadas; 8.4 arreglos menores y considera que sólo 5.4 millones no tienen problemas. Este cálculo ya sugiere un universo de poco 
más de 16 millones de déficit, aunque parte sean requerimientos menores. La estimación de viviendas con problemas de calidad es de 13.5 millones, mientras que en nuestra investigación el cálculo fue de 11.1 millones, incluyendo la seguridad jurídica y la accesibilidad; en cuanto a viviendas nuevas, el estudio del Cidoc (2006) habla de tres millones mientras que el nuestro, de 10.9 millones, pero si se restan los hogares derivados de extensiones familiares se llega a 2.75 millones, datos consistentes con los tres millones propuestos por el Cidoc, aunque nuestros datos sean más conservadores.

Las diferencias con las estimaciones presentadas por el Cidoc (2006) se explican fácilmente. Su propuesta se basa en la construcción de un índice 0-10 que se forma según el cumplimiento de 10 atributos, cada uno de los cuales aporta un punto: servicios (4), existencia de electricidad, agua, drenaje y gas para cocinar; materiales (3), muros de tabique, techo de concreto o ladrillo, piso que no sea de tierra; y espacio (3), que cuente con cocina que no se use como dormitorio, baño y promedio de ocupantes por dormitorio menor a 2.5. Como se puede observar, los conceptos presentados en la publicación del Cidoc son muy semejantes a los utilizados en este trabajo pero el tratamiento metodológico es muy diferente; en aquél caso se construye un índice simple con base en presencias (1) y ausencias (0), por lo que no es posible conocer con detalle la naturaleza del déficit; por otra parte, no incluyen a las familias que se ubican en hogares extendidos, y la sobreestimación del déficit del Cidoc seguramente se relaciona con que no consideran adecuadas las techumbres diferentes al concreto y al ladrillo, aunque en el propio documento se reconoce que esto no necesariamente debería ser así y que algunos materiales convencionales podrían ser adecuados.

De los contrastes de las tres estimaciones anteriores (Conafovi, Cidoc y esta investigación) fácilmente se llega a la conclusión de que:

- Hay una enorme coincidencia conceptual respecto de lo que se debe considerar como déficit.

- Las estimaciones de la Conafovi son excesivamente bajas en relación con las otras dos fuentes.

- El planteamiento de esta investigación es más moderado que el del Cidoc, sin embargo, ni el Cidoc ni la Conafovi consideran el rezago derivado de las extensiones familiares. 
La diferencia de la Conafovi quizá podría explicarse como el sesgo político derivado de la dificultad de reconocer una problemática de vivienda que es mucho más compleja de lo que se solía imaginar o de lo que los ciudadanos pueden comprender. El hecho es que el problema de vivienda en México (léase pobreza) es bastante más extenso que lo que se reconoce.

Por otra parte, la muestra censal ofrece una fuente mucho más sólida y detallada para estimar el déficit pues permite vincular los resultados con otras variables, como la edad e ingreso de los jefes de familia, la situación de derecho a instituciones de vivienda y otras que pueden ser instrumentos de análisis muy útiles para el correcto diseño de la política de vivienda.

Es grave que se ignore el problema de familias extendidas, que suma cerca de 14.6 millones de personas, de las cuales se pueden reconocer 7.4 millones de familias que no cuentan con una vivienda y tampoco con los suficientes recursos para tener independencia financiera. Claro que esto va más allá del problema de la vivienda, pero no por ello se debe ignorar. De hecho, el problema más serio para la política de vivienda son estos 7.4 millones de familias que tienden a solucionar su situación a través del hacinamiento y la dependencia económica.

Al tener en cuenta estos resultados, parece claro que la política de vivienda del gobierno foxista estuvo muy mal concebida en varios aspectos. No se trata de un problema de esfuerzo o recursos financieros, que sin duda se pusieron en la mesa, sino de una política mal concebida y débil en la comprensión de la magnitud y naturaleza del problema. Como lo establece el Programa de Indicadores Urbanos de la onU, "los malos resultados del tema de vivienda son producto de las políticas, no de las inversiones" (onu, 1987). La política actual es muy amplia e intensa pero poco diversificada y atiende exclusivamente un tipo de problema y segmento. Ha sido innovadora en la cuestión financiera, pero tiene grandes vacíos derivados del desconocimiento de cómo se las arreglan las familias para vivir.

Una estimación del rezago considerando la naturaleza de éste, como se presenta en nuestra investigación, y que cada vez se tipifica más en función de la condición urbano-rural, las entidades federativas y la situación de derecho a alguna de las instituciones de vivienda, como el Infonavit y el Fovissste, puede ser la base para diseñar una política diversificada de vivienda que responda puntualmente a las necesidades y condiciones de las familias mexicanas. No existe un solo problema de vivienda o una 
sola forma de rezago, sino una diversidad de situaciones que requieren soluciones e instrumentos más específicos para cada caso.

El diagnóstico que aquí presentamos debe considerarse un primer paso para conocer las soluciones habitacionales de facto, sin embargo, reconocemos que será necesario profundizar en ciertas temáticas, como la naturaleza, condición y evolución de las extensiones familiares; el efecto de la vivienda mínima y de interés social en las condiciones de vida, principalmente si contribuyen al desdoblamiento de las familias extendidas o si mantienen los mismos esquemas de ocupación. Por otra parte, también será necesario profundizar en las diferencias regionales del déficit y según algunos factores como la condición urbano-rural, la edad del jefe de familia y la situación de los ingresos, todo lo cual supone un análisis de datos muy extenso. Por desgracia, las bases de datos que utilizamos, por su propia naturaleza muestral, no permiten hacer inferencia a mayor escala como podría ser una ciudad o un municipio, lo que sería útil para definir las necesidades de vivienda por localidad.

Por otra parte, teniendo en cuenta que una estimación detallada como la presentada aquí depende de información censal directa, es decir, de la muestra, y que ésta se publicó por primera vez en el año 2000, se requerirá de la muestra censal del año 2010 para establecer la dinámica del déficit y, en particular, el efecto de la política de vivienda iniciada en el año 2000 con el gobierno de Vicente Fox y que aparentemente tendrá continuidad en los próximos años.

Un tema particularmente importante que se debe abordar es la implicación de la política de vivienda en los temas urbanos y sobre todo con la política de suelo. Se está produciendo un modelo de ciudad totalmente irracional que resultará en un alto costo social y ambiental en el futuro y un fuerte costo para los ocupantes de las viviendas, cuyo aparente ahorro al obtener la vivienda se convertirá en un sobrepago en transporte de por vida.

En fin, es claro que la política de vivienda se concibió sólo desde la perspectiva financiera y de la construcción, pero es una política incompleta que no está logrando abatir el problema y sí está creando nuevas dificultades urbanas, territoriales y sociales. 


\section{Bibliografía}

Barrientos-Rodríguez, Alonso (1972), "Procedimiento para el cálculo de los costos de mantenimiento", Centro Regional de Construcciones Escolares para América Latina y el Caribe Conescal, 26, México, pp. 24-34.

Cidoc (Centro de Investigación y Documentación de la Casa) y Joint Center for Housing Studies de la Universidad de Harvard (2004), El estado de la vivienda en México, Consejo Nacional de Ciencia y Tecnología, México.

Cidoc y Sociedad Hipotecaria Federal (SHF) (2006), El estado actual de la vivienda en México, Cidoc-SHF-Convavi-JCHS, México.

Cervantes J. y E. Oliver G. (2005), "La habitabilidad, una visión psicoambiental y sus repercusiones en los estilos arquitectónicos de megaconjuntos habitacionales”, en Esther Maya Pérez y Jorge F. Cervantes Borja (coords.), La producción de la vivienda en el sector privado y su problemática en el municipio de Ixtapaluca, Plaza y Valdés-Universidad Nacional Autónoma de México, México, pp. 75-98.

Conafovi (Comisión Nacional de Fomento a la Vivienda) (s/f a), Rezago habitacional. Necesidades de vivienda, disco compacto, Conafovi, México.

Conafovi (Comisión Nacional de Fomento a la Vivienda) (s/f b), Programa Nacional de Vivienda 2001-2006, Conafovi, México.

Comisión Nacional de Fomento a la Vivienda (Conafovi), en $<$ www.conafovi.gob.mx>, marzo 2004.

Coplamar (Coordinación General del Plan Nacional de Zonas Deprimidas y Grupos Marginados) (1982), Vivienda: necesidades esenciales en México, situación actual y perspectivas al año 2000, Presidencia de la República-Coplamar, Siglo XxI, México. 
Cortés, Yves (2001), Instituciones públicas de ordenamiento y construcción en Burdeos, Secretaría de Desarrollo Social, México.

Chi-Ong Shin (2002), "Segregation and marginalization within public housing: the disadvantage in Bedok New Town, Singapure", Housing Studies, 17(2), Routledge, pp. 267-288.

El Mercurio, "Poco espacio a lo largo del tiempo", Chile, edición en internet < http://diario.elmercurio.com, 26 de enero de 2002.

Ennals, Meter y Deryck W. Holdsworth (1998), Homeplace. The Making of the Canadian Dwelling over three Centuries, University of Toronto Press, Toronto.

Esquivel-Hernández, María Teresa (2005), "Los habitantes de San Buenaventura", en Esther Maya Pérez y Jorge F. Cervantes Borja (coords.), La producción de la vivienda en el sector privado y su problemática en el municipio de Ixtapaluca, Plaza y Valdés-Universidad Nacional Autónoma de México, México, pp. 51-74.

Friedman, Avi y Vince Cammalleri (1994), Construction industrialisée des maisons en rangée au moyen de panneaux muraux: la maison évolutive, version industrialisée v, 104 pp., Estudio realizado a petición de la Société d'Habitation du Québec et de la Société Canadienne d'Hypothèques et de Logement, Québec.

Garza, Gustavo y Martha Schteingart (1978), La acción habitacional del Estado en México, El Colegio de México, México.

INEGI (Instituto Nacional de Estadística, Geografía e Informática) (2001), Base de datos y tabulados de la muestra censal del XII Censo General de Población y Vivienda 2000, disco compacto, Aguascalientes, INEGI.

Koebel, Theodore y Margaret S. Murria (1999), "Extended Families and their housing in the us", Housing Studies, 14(2), 125-143. 
Maya-Pérez, Esther y Jorge Fernando Cervantes-Borja, (coords.) (2005), La producción de la vivienda en el sector privado y su problemática en el municipio de Ixtapaluca, Plaza y ValdésUniversidad Nacional Autónoma de México, México.

Michel Díaz, Marco Antonio (1992), Conferencia en las Audiencias Públicas de Información y Análisis sobre el Problema de la Vivienda en el D.F., México.

ONu (Organización de las Naciones Unidas) (1987), Programa de Indicadores Urbanos (Programa de Indicadores de Vivienda), ONU-Hábitat-Banco Mundial, Nairobi.

Rodríguez, Jorge y Sebastián Carrasco (2002), "Una metodología para estimar el déficit habitacional usando datos censales", Redatam Informa, publicación de la División de Población de la Comisión Económica para América Latina y el Caribe (CELADE-CEPAL), LC/L 1812, vol. 8.

Pinch, Steven (1997), Worlds of Welfear, Routlege, Londres-Nueva York.

Poblett, Martha (2002), Diálogos Infonavit, 30 años, Infonavit, México.

Roberge, Anne (1996), "Quand un toit seul ne suffit plus: les services pour les families en logement social”, Adaptación de la vivienda a las nuevas realidades sociales, coloquio organizado por la Société d'habitation du Québec, mayo de 1995.

Romero-Vadillo, Irma (2005), "La política habitacional y el hábitat del siglo xxı", tesis de doctorado en urbanismo, Universidad Nacional Autónoma de México, México.

Samuelson, P. A. (1954), "The pure theory of public expediture", The Review of Economics and Statistics, 36, Harvard University's Kennedy School of Government, Cambridge, Massachusets, pp. 387-389.

Teasdale, Pierre (1996), "Espace domestique et multiciplité de modes de vie: resultats de quelques recherche relatives a 
l'adaptabilité du logement", Adaptación de la vivienda a las nuevas realidades sociales, coloquio organizado por la Société d'habitation du Québec, mayo de 1995.

Travers, Max (2004), “The philosophical assumptions of Constructionism", en Keith Jacobs, Jim Kemeny y Tony Manzi (eds.), Social Constructionism in Housing Research, Hampshire, Ashgate.

Verret, Robert (1999), L'Àdaptation de l'habitat au Viellissement de la population: actes du symposium de la Société d' habitation du Québec á la 4e. conference mondiale de la Federeation internacionale du vieillissement., 59 p. Les entretiens sur habitat http://shq.gouv.qc.ca/en/pu/puind00. html-Sujet05

Villavicencio, J., A. Durán, M. Esquivel y A. Giglia (2000), Pobreza, vivienda y politica habitacional. Las condiciones de vida en la vivienda de interés social en la Ciudad de México, Porrúa-Universidad Autónoma Metropolitana Azcapozalco, México.

Winfield-Reyes, Fernando (2000), "La vivienda estatal planificada en México, 1925-1988", tesis de doctorado, Universidad Politécnica de Madrid, Madrid.

Recibido: 22 octubre 2006. Aceptado: 9 de febrero de 2007.

Ignacio Kunz Bolaños. Es doctor en urbanismo; actualmente es investigador del Centro de Investigaciones y Estudios de Posgrado de la Facultad de Arquitectura de la Universidad Nacional Autónoma de México. Es miembro del Sistema Nacional de Investigadores (SIN), nivel II. Su línea de investigación se centra en: demografía de la vivienda y reestructuración urbana. Entre sus publicaciones destacan: "La fiscalidad para la regeneración de las áreas centrales", en René Coulomb (ed.), Proyectos estratégicos para la Áreas Centrales de las Ciudades Mexicanas”, Secretaría de Desarrollo Social, pp. 191-212 (2005); "Los centros de ciudad. Problemas y oportunidades”, en René Coulomb (ed.), 
Proyectos estratégicos para los centros de ciudad en México. Guía metodológica, México, Secretaría de Desarrollo Social, pp. 2750 (2005); "Familias extendidas en el Distrito Federal. Un problema oculto de vivienda", en Fernando Greene C. (comp.), Urbanismo y vivienda, México, Universidad Nacional Autónoma de México, pp. 396-404 (2005).

Irma Guadalupe Romero Vadillo. Es doctora en urbanismo; actualmente es investigadora del Centro Interdisciplinario de Investigaciones y Estudios sobre Medio Ambiente y Desarrollo del Instituto Politécnico Nacional. Su línea de investigación actual se centra en implicaciones territoriales de la política de vivienda. Entre sus publicaciones destacan: "El déficit de vivienda", en Fernando Greene C. (comp.), Urbanismo y vivienda, México, Universidad Nacional Autónoma de México, pp. 454-463 (2005); "Interdisciplinariedad y transversalidad en la política habitacional, una necesidad imperante", ponencia presentada en el 1er. Congreso Nacional de Medio Ambiente y Desarrollo, SedesolSemarnat, INEGI, IPN (2005); "La planeación como una solución ambiental. El ordenamiento ambiental del territorio de las ciudades", ponencia presentada en el Congreso Nacional Femisca Soluciones ambientales para un desarrollo pleno (2006). 